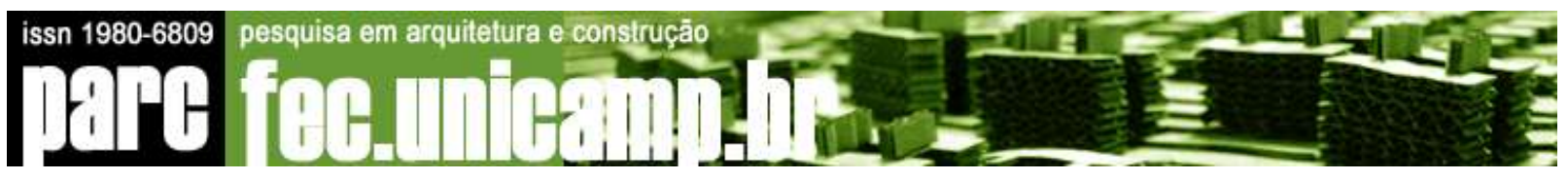

\title{
PRÁTICA INTEGRADA EM ARQUITETURA, ENGENHARIA E CONSTRUÇÃO
}

\author{
JULHO 2011 \\ PROFA. DRA. MARINA SANGOI DE OLIVEIRA ILHA \\ PROFA. DRA. VANESSA GOMES DA SILVA \\ (EDITORAS)
}

Esta edição da parc apresenta uma seleção de artigos publicados na Conferência Sustainable Building 2010 Brazil (SB10Brazil), em novembro de 2010 na cidade de São Paulo.

A SB10Brazil foi organizada pela Faculdade de Engenharia Civil, Arquitetura e Urbanismo da Universidade Estadual de Campinas, pela Universidade Federal do Espírito Santo e pela Universidade Federal de Santa Catarina.

Das 210 submissões de resumos estendidos para apreciação, foram considerados conformes aos critérios e temas cerca de 100 (cem) resumos estendidos de trabalhos, provenientes de 11 países. Todos os trabalhos passaram por uma avaliação cega de pelo menos 2 avaliadores, os quais constam como Comitê Científico ad hoc desta edição da parc.

Os artigos constantes nessa edição enfocam alguns dos temas discutidos na SB10Brazil: modelos urbanos e infra-estrutura sustentáveis; projeto e construção avançados; metodologias e ferramentas de avaliação da sustentabilidade; avaliação do desempenho ambiental de sistemas e componentes e gestão sustentável de facilidades.

Carputti discute aspectos relacionados com projeto integrado de uma região urbana tendo em vista os conceitos de sustentabilidade em que, a partir de um estudo de caso desenvolvido em Paris, França, são levantadas questões sobre os espaços necessários para a implantação de medidas de mitigação dos impactos ambientais, tais como os diferentes usos previstos para o solo e para as coberturas das edificações: será que as cidades do futuro exigem mais espaço? 


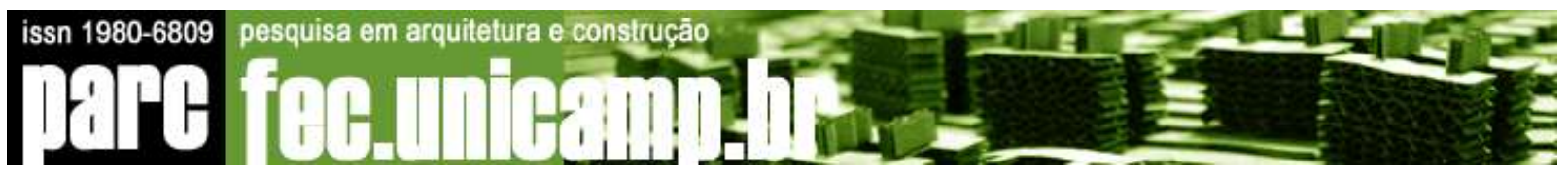

Apesar de vários avanços ocorridos tanto na área acadêmica como mercadológica, a demanda e a penetração de edificações mais sustentáveis ainda não é satisfatória. Nesse sentido, Lützkendorf analisa o papel de todos os envolvidos na geração de um empreendimento para a mudança desse cenário.

Gomes e Pardini discutem a aplicabilidade da certificação ambiental de edifícios norteamericana LEEDTM e do conceito de custos ao longo do ciclo de vida em empreendimentos mais sustentáveis no Brasil, apresentando as principais dificuldades envolvidas. Duas edificações comerciais, as quais foram os primeiros empreendimentos buscando a referida certificação no país, constituíram os estudos de caso desse trabalho.

Saade et al apresentam uma análise de ciclo de vida simplificada do aço e das escórias siderúrgicas, com uma avaliação comparativa dos resultados decorrentes do uso de critérios de alocação de impactos com base na massa e no valor econômico; e, mais especificamente, a diferença entre os resultados obtidos a partir do uso de dados de inventários internacionais e de dados específicos de uma empresa siderúrgica brasileira.

Kozak et al analisam a efetividade do projeto arquitetônico assistido por simulações de desempenho computacionais e em laboratório, tendo como objeto de estudo a edificação destinada a um centro de proteção da biodiversidade na Patagônia argentina.

Dentro desse mesmo contexto, Leister e Abu-Hijleh analisam o impacto da aplicação dos conceitos de arquitetura bioclimática na redução do consumo de energia em edificações de interesse social no Brasil, evidenciando que mesmo pequenas modificações podem levar a resultados significativos no que se refere ao uso eficiente de energia.

O aumento do escoamento superficial decorrente da impermeabilização das cidades e a escassez de água têm motivado o emprego de sistemas de aproveitamento de água pluvial nas edificações. Quando se tratam de coberturas verdes, existe ainda o benefício de melhoria do conforto térmico, com o conseqüente uso mais eficiente de energia. Nesse sentido, Ibiapina et al descrevem os materiais e métodos de uma investigação que vem sendo desenvolvida na Faculdade de Engenharia Civil, Arquitetura e Urbanismo da Universidade Estadual de Campinas para avaliação da qualidade da água e capacidade de retenção de 


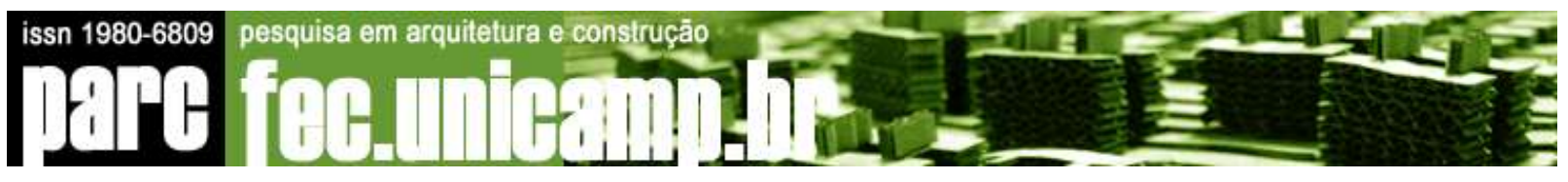

água pluvial em coberturas verdes instaladas em células-teste tendo em vista avaliar o potencial de sua aplicação para a conservação de água nas edificações.

Por fim, tendo em vista a redução da carga nos sistemas urbanos de esgoto sanitário e recarga do lençol freático, Pitaluga et al apresentam os resultados de uma avaliação da eficiência do sistema de zonas de raízes no tratamento do esgoto sanitário em uma estação de tratamento experimental na Escola de Engenharia Civil da Universidade Federal de Goiás.

Marina S. de Oliveira IIha

Vanessa Gomes da Silva 